\title{
When Peaceful People Fight \\ Beyond neutralization and subcultural theory
}

Sveinung Sandberg, Heith Copes, Willy Pedersen

This is a post-print version. Please use this reference if citing the article:

\begin{abstract}
Fights are widespread in society, but for most people it happens once or twice and is not part of a consistent pattern or lifestyle. Using a narrative criminological framework, we study the stories of violence among people who otherwise seldom engage in violent behaviour. The young Norwegians we interviewed, emphasised that their fights emerged as a response to insults, was fuelled by drinking and could be exciting. Participants had negative evaluations of their fights, took the blame for them, talked down their importance and selfcritically used humour to ridicule their involvement. Our study demonstrates the shortcomings of subcultural and neutralization theories when it comes to understanding violent behaviour among those who rarely engage in it.
\end{abstract}

Keywords: Narrative criminology, subcultural theory, neutralization, violence, fights, 


\section{When Peaceful People Fight: Context, Conflicts, and Retrospective Evaluation}

Scholars who study street fighting typically focus their attention on violent populations that embrace violence as a form of retaliation, as a means of gaining respect, or as an indicator of character. Those working in this field often use a subcultural framework to understand the facilitators and constraints of these violent actions (Ilan 2015). Subcultural researchers addressing violence draw on samples of people involved in serious and continuous violence (Ellis 2016), often examining incarcerated populations (Brookman et al. 2011; Heber 2017), people who deal drugs (Topalli, Wright and Fornango 2002; Bucerius 2014), those who use weapons when fighting (Gong 2015), or members of violent street gangs (Garot 2010; Fraser 2017). For the people being studied, violence is an important way to demonstrate adherence to cultural values and to construct personal identities. While individual subcultures of violence vary, they tend to account for their actions similarly. Specifically, they share the belief that violence is acceptable in some situations (e.g., in response to perceived disrespect, as a way to gain excitement and thrills, or as a means of retaliation) and that reputation and respect can be gained by being willing and able to fight (Anderson 1999).

The subcultural tradition has provided a wealth of information on how people who value fighting as a sign of character make sense of and justify their violent actions (e.g. Wolfgang and Ferracuti 1967; Anderson 1999; Bourgois 2003). However, few qualitative criminological studies of fighting have focused on populations that do not regularly engage in violent behaviour or where fighting is not seen as an integrated part of identity and culture. When populations less committed to violence are addressed, scholars typically do so from the context of neutralization theory (Sykes and Matza 1957) or drift theory (Matza 1964), 
which suggests that people use linguistic devises to neutralize potential negative self-perceptions associated with norm violations to drift back and forth between conventional and deviant behaviours. Neither perspective is well-suited to explain violence that occurs among those who engage in violence rarely and in specific situational contexts.

We study the way people talk about their fighting behaviour outside of cultural contexts where violence is valued as an identity marker. We argue that using a narrative theoretical framework will give insights into how different groups make sense of fights beyond simple neutralizations or subcultural acceptance. Doing so can help outline the contours of different belief systems relating to violence. Specifically, we explore the ways that young people who do not identify with a violent subculture not only explain but evaluate their participation in fights. By analysing how they evaluate their fights we go beyond simple neutralizations and subcultures to show how narratives can constrain behaviour.

Our findings demonstrate that the reasons for fighting given by these 'peaceful' people resemble those given by people who more frequently engage in violence (either as neutralizations or as subcultural acceptance). The two groups do however evaluate the fights in vastly different ways. We furthermore argue that these narrative evaluations are more than simple attempts to understand or deal with these episodes after-the-fact. Rather, they shape future action, by constraining future fighting, rather than encouraging it. Our study thus highlights the strength of using a narrative criminological framework, rather than a subcultural or neutralization framework, when studying stories of violence.

\section{Violence in Subcultures and Nightlife}

Work on violent subcultures suggests that defending one's honour and establishing a reputation are valued traits in some environments; however, subcultures do differ in proscribing what 
types of situations demand violence and the nature of acceptable violence (Copes, Hochstetler, and Forsyth 2013). Indeed, street culture is a spectrum of beliefs that ranges from mainstream youth culture to criminal groups (Ilan 2015). While there is variation in subcultures of violence, they do share a general belief that the use of violence is acceptable when defending honour, responding to insults, and establishing reputations as willing combatants. Anderson's (1999) discussion of the code of the street suggests that its adherents value a retaliatory ethic and value physical aggression. Other codes of violence promote violence only as a defensive strategy to be used when threatened (Nisbett and Cohen 1996). For example, the Southern culture of honour in the United States is portrayed as a defensive strategy and is more widely held than the code of the street. Such a code proscribes relatively narrow allowances for use of force; namely, in response to protecting one's honour and one's property (Nisbett and Cohen 1996; Miller 2011).

Not all who engage in violence fully accept the symbolic, social and cultural importance of violence and many do not necessarily define themselves based on their propensity to fight. People who code switch (i.e., shifting expressions of two or more cultural beliefs based on the situation) often describe their violence as an unwanted but necessary action to ward off future assaults by people who do live by a violent retaliatory ethic (Anderson 1999). People encounter multiple and diverse cultural models, including conventional beliefs as well as oppositional ones (Harding 2010). They can then draw from each of these cultural models as they need to and adjust situationally, while not committing fully to any one of them (Lindegaard 2018). For example, the evaluations of fights among people who codeswitch can differ considerably from people who construct violence as a positive means of developing a reputation (e.g., those who value 'the code of the street'). They still approve of fights and integrate (although sometimes reluctantly) the ability to fight as an essential part 
of their self-identity.

Historically, neutralization theory has been the most important alternative to subcultural theories in criminology. Researchers have used it to explain how and why people who appear to be committed to conventional values violate these norms (Sykes and Matza, 1957). Matza and Sykes (1961) claimed that mainstream culture includes some suppressed 'subterranean values' (excitement, thrill-seeking), and that delinquent behaviour is an expression of these values. Arguing that people experience guilt or a negative self-image when violating norms in which they believe, Sykes and Matza (1957), suggest that people can neutralize the guilt of their action by using one or more linguistic technique that blunt the moral force of the law. People who accept neutralizing beliefs pertaining to violence (e.g., in response to disrespect or to protect others) are more likely to engage in violence than those who do not accept such beliefs (Agnew 1994). By relying on these neutralizing techniques people can remain committed to a belief system, yet situationally violate it without doing harm to their self-concept. In short, they can drift between cultural belief systems.

The ability to remain committed to one belief system but situationally draw from others can explain fights among 'ordinary' people. One problem with neutralization theory, however, is that studies in this tradition tend to use samples of people who repeatedly engage in deviance (Maruna and Copes 2005). The link to mainstream society is therefore weak and in many cases, these samples could have been used for subcultural studies as well. While these samples are well suited for showing that those in the subculture also are committed to mainstream values - which is one of neutralization theory's main arguments - they are less relevant when studying delinquent behaviour in the general population. Accordingly, we use a more heterogeneous qualitative data set than do subcultural, neutralization, and 
more recent studies emphasising neo-liberalism (Winlow and Hall 2006) or mainstream masculinity (Ravn 2018) as explanations for violence. Doing so allows us to nuance criminological depictions of violence in the general population.

\section{Narrative Criminology and Fight Stories}

We take a narrative criminology approach (Presser and Sandberg 2015; Sandberg and Ugelvik 2016) to understand how generally nonviolent individuals evaluate and make sense of their fighting. This approach emphasises the importance of narratives for both explaining past behaviours and encouraging future ones. Narratives are often defined as a discursive form that combines temporality (at least two events, where one event follows the other in time) and causality (one event leads to the other). These two components create the plot that gives a narrative meaning (Polletta et al. 2011). Labov (1972) argues that narratives have formal properties, each with its own function. In general, narratives are comprised of six elements: abstract, orientation, complicating action, resolution, evaluation and optional coda. While each component is important, criminologists studying social identity have been mostly concerned with evaluations (so what?) and codas (what does it all mean?). These elements of narrative are particularly good at illustrating the cultures and codes that facilitate and constrain violence.

For most people who get into physical fights, the events are extraordinary episodes. They are dramatic, risky events where much is at stake. Because episodes of violence are dramatic events, people will have a strong need to interpret these events through storytelling (Morrill et al. 2000). We argue that the way storytellers evaluate stories of violence is just as important as the factual details of the events when trying to understand the conse- 
quences they have for personal identity and continued behaviour. A particular fight can happen on impulse or as part of being carried away in a transgressional sphere or 'moral holiday' (Collins 2008) like nightlife, but the narrative evaluation of it afterwards must be integrated into the larger life projects and life-stories of fighters when storytellers 'moralise' the events. Fights can for example be described as expected following subcultural values or justifiable and in accordance with more mainstream values, but as we show in this study, they can also be narrative resources to describe who the fighters are not.

In social contexts characterised by a subculture of violence or an honour code, people use stories of violence to enact identities as fascinating people (Jackson-Jacobs 2004), organise hierarchies and negotiate rules (Lauger 2014), and establish masculinity (Tomsen 1997, Hochstetler, Copes and Forsyth 2014). The evaluation of fight stories is often done in a way where storytellers portray themselves as respectable people who heroically defended their honour (Copes, Hochstetler, and Forsyth 2013). In violent subcultures, fights are evaluated positively, as long as they are carried out within the confines of acceptable rules. This often means neutralizing violence by referring to 'higher loyalties', 'denying victims', 'denying responsibility' or 'denying injury' (Sykes and Matza 1957). The opposition between neutralization and subcultural theory is often a false one, because populations committed to a subculture tend to neutralise (Sandberg 2009; Jacobs and Copes 2014) and because both frameworks focus on persistent offenders and are trying to explain continuous involvement in crime.

Narrative criminologists argue that people make use of a broad variety of cultural narratives when telling their personal narratives (Loseke 2007). By drawing on larger cultural ideals, storytellers can make sense of their actions by situating themselves within a specific context or shared storyline (Presser and Sandberg 2015). This idea assumes that people 
draw on pre-existing stories when creating personal identity narratives, and that those analysing stories should pay particular attention to components of the story that reveal motives endemic to character projects (Katz 1988). The framework of narrative criminology pays attention to language and emphasises viewing 'crime and other harmful action as a function of the stories that actors and bystanders tell about themselves' (Presser 2012: 5). That is, narrative criminologists believe that stories can shape storytellers' future actions (criminal or not), reveal imagined expectancies, and provide templates for action. Importantly, researchers must look at extensive narratives to fully understand the role they play for the storyteller.

We are interested in the basic questions of how people explain why they get involved in fights and what they think about these fights. That is, we seek to understand how people evaluate their stories to project personal identities. We focus on a group of people who are seldom involved in fights (having only been involved in one or two in their lives). Our aim is to understand their explanations for why the fight occurred and to scrutinise how they evaluate their actions afterwards. In this way, we hope to better understand what generates violence among those who ordinarily condemn it and point to possible reasons they do not continue with violence.

\section{Method}

The data in this study are taken from a sample of semi-structured interviews with 104 young adult Norwegian partygoers. To fit the sampling criteria, participants had to drink excessively and frequently, take part in the night time economy, and infrequently engage in fights (fewer than three fights in their lifetime). This sampling procedure allowed for a sample of people who had been in fights, but who did not consider themselves to be violent. We have 
removed four individuals, all men, from the sample who were experienced with fighting and who fundamentally associated with violent subcultures, leaving us with 100 participants. These four men had all taken part in several hard fights, they had elaborate stories to justify such recurrent violence, and for them violence was an important way to construct their personal identities. Although participation in fights was not part of the initial selection criteria for this study, 65 of the participants described a total of 83 episodes of violent fighting (i.e., at least one person physically struck another). Of these 83 events, 41 referred to other people fighting (e.g., friends), 23 referred to themselves being victimised and fighting back, and 19 referred to themselves as instigating or contributing to the fight. Our findings are based on these 65 heavy episodic drinkers who talked about violent fights but who did not adhere to a subculture of violence, with an emphasis on those 42 who had been directly involved in the incident.

Participants were recruited by seven research assistants (three women and four men in their mid-to late 20s) who were trained sociologists from the University of Oslo. These assistants recruited participants from different areas in Norway using snowball-sampling techniques. The sample was designed to reflect the normal population of partygoers and visitors in the night-time economy in Norway. One out of five participants lived in Oslo and the remainder came from other parts of Norway. This distribution matches the larger population of Norway. Participants included in this subsample ranged in age from 18 to 32, with a mean age of 25. Participants were either still in school or working full- or part-time. Their educational level was slightly above that of the population level in their age group. The subsample consisted of a slightly higher number of women $(n=36)$ than men $(n=29)$. However, the men said that they played a more active role in the fights ( 21 out of 29 , or $72 \%$ ) than did the women ( 21 out of 36 , or $58 \%$ ). 
In analysing the data, we found that women and men, by and large, described similar reasons for fighting and had similar evaluations of their fights. While there were subtle differences in motives described by men and women (e.g., the events that they found disrespectful and the severity of violence used), we found that the larger themes for explanations and evaluations were similar. The many women involved in fights and the relatively small gender differences found in evaluations of fights is likely due to the 'normal' sample of partygoers and the fact that they had been involved in few overall fights. By including both women and a broader selection of men than studies in both the subcultural and neutralization tradition, we shed light on behaviours that are primarily studied with male 'risk-seeking' samples that assume a more direct relationship between men, masculinity, and violence (see e.g., Ravn 2018).

The interviews were conducted by the same researchers who recruited the sample. Interviewers used a semi-structured interview guide that was designed to foster a conversational interview and to encourage participants to elaborate on what they found important, while still asking and probing about specific topics. To aid in consistency in the interviews, two of the authors trained all interviewers. The interviews lasted between 90 and 120 minutes, and included general topics such as descriptions of the social contexts where they used alcohol, the experience of intoxication and drunkenness, flirting and 'hooking up,' and episodes of violent fighting. We asked relatively open questions such as 'have you been involved in, or witnessed a fight?', and follow-up questions such as 'can you describe what happened?'

We audio recorded the interviews (with participants' permission) and then transcribed them. During transcription we removed identifying information (all names included 
are aliases assigned by the research team). We coded the transcribed interviews using HyperRESEARCH. When analysing interviews, we first coded broadly for a variety of themes, one of these was violence. We continuously checked for consistency by letting several researchers code the same interviews. Violence was initially a straight-forward category including all forms of talk about violence in the transcripts. The second stage of coding was more detailed and involved categorising participants' explanations for fighting and how they evaluated the incidents. The final stage of coding consisted of selecting representative quotes that reflect the larger themes of the analysis.

\section{Explaining Fights}

Violence was not a regular occurrence among the participants; nevertheless, 42 said that they had participated in a physical fight at least once as an adult. Perhaps because of the rarity of these events in their lives, participants were able to describe their fights in detail, including who was involved, where it happened, and why they thought it occurred. Participants said they fought: as a response to perceived insults, as a source of excitement, and as a result of the chaos and poor decisions caused by excessive intake of alcohol. While we discuss these stated motives as separate categories, they were often intertwined in participants' accounts and should be viewed as ideal types.

\section{Fights as Response to Perceived Insults}

The most common explanation participants gave for why they fought was because they believed they had been insulted or disrespected. Participants said that they engaged in the fight as a way to save face or to regain the position they believed was in jeopardy. This 
was the case for both men and women. Heidi said that her fight was because a stranger made a derogatory comment about her nails and then refused to apologise for the remark: She told me I had ugly nails. That's what set the whole thing off. [My friends and I] first went back to the car, and said, 'We should go back. We just confront her,' things like that. And I was just like, 'Fuck, let's do it,' right. I was a little tipsy too and, 'No, now we're going to be tough too,' yeah. So we went back to her. My friend who was with me, was just like, 'Yeah, come on'. She did nothing, she just like egged me on more and more. [She] was just like, 'Come on'. So then I asked her just like that, 'Yeah, what's your problem,' and things like that, right. And she just, 'Oh, can't you please'. She was stuck-up, and, 'Oh can't you please just go away and,' like that, and pushed me, and I was just like, 'Ah, push me one more time and you'll see'. As evident in her description, Heidi saw a series of insults emanating from the antagonistthe comment about the nails, the lack of apology, and finally the pushing. At each step Heidi could have withdrawn or reinterpreted her adversary's actions to de-escalate the situation, which was generally the norm among the participants (see Athens 1997). However, she did not and ultimately hit the woman who insulted her. As she said:

Well, she was a head taller than me, right [laughing]. But anyway, so I just like took my fists - I had never done that before, hit someone for real, that is-so then I just like clenched my fist, and went towards her, right. Right into her jaw like that. And then I took my elbows, and went like this [mimicking the move] because, right, because she was taller than me, so I just did like this and, took my elbow up, and just got like. Her head snapped backwards. 
Although Heidi had never hit someone before, her description of the episode shared many similarities with how fights are described among people who are more familiar with fighting and who seek to save face or account for their violence.

Jon was also unfamiliar with fighting, but said that insults led to him being goaded into a fight. He and friends were standing outside a nightclub when some strangers commented on the dialect they spoke and started mocking the football team from their hometown.

Jon: It was a lot of talking shit at first. It was like [mimics his dialect], 'This is our city, you all go home. Viking sucks'. Then my friend started with some Viking shout-outs [started to sing], something like that [laughter]. So then one of them got fucking pissed, and pushed him. It was totally fucked up, so then I hit him in the face. Interviewer: So your first reaction was to hit him? Jon: Of course it wouldn't usually have been my first reaction, but I was drunk. So there you have it. And I got fucking angry, because they were so fucking retarded. ... And then it was this, it's this honour thing, 'You don't fucking push my friend,' things like that.

The violent episode ended with Jon getting beaten to the ground and him running off to avoid more trouble. While not accustomed to fighting, Jon was the first one to initiate physical violence. He explained his fighting as a result of 'honour' connected to the importance of standing up for his friends.

From a perspective of neutralization theory, the way participants described insults and the desire to protect honour could be interpreted as 'appeal to higher loyalties' and the emphasis on the opponent starting the fight as 'denial of victim' (Sykes and Matza 1957). However, as indicated by Jon's comment that 'it was totally fucked up' participants' showed 
few signs of such 'loyalties' to honour cultures nor did they really deny there being a victim. Reducing these stories to neutralizations is therefore problematic. Moreover, and in ways resembling the cultural values of violent subcultures (e.g. Anderson 1999), men and women partygoers said they engaged in violence to restore justice after perceived insults. Commitments to these values, however, were situational and temporary, and constrained to short episodes in the context of nightlife and partying. It seemed they drew on larger subcultures of violence values for the situation, but did not fully accept the subcultural identity.

\section{Fights as Exciting Experiences}

While perceived insults and disrespect were explanations for the majority of the fights in this study, the young partygoers also said that they got involved in fights just for the 'hell of it'. Excessive drinking is often coupled with different forms of transgressions (Tomsen 1997), and while fighting did not dominate these experiences, it was part of the repertoire of a night on the town. The pleasures of the night-time economy were associated with being among crowds of revellers, being 'hyped up,' and 'experiencing a rush' (MacLean and Moore 2014), all of which can facilitate aggressive behaviour. Sigurd described a fight at a kebab place, where he and friends had a meal after a long night out:

One of my friends got into some bickering with the others: two guys and a girl. The girl sprays soda on my friend, and my friend responds by throwing a kebab in one of the guy's face. Then the whole thing started. I was actually quite drunk, but what they have told me afterwards, is that I said that we should take it one-on-one across the street. That's where I hit him first and where he hits me after, right under the eye, and then he throws himself on top of me and we roll around, but then it tapers 
off in a way because the ones that work at the kebab place they come out and calmed us down, and me and my two friends went home.

Throughout the interview Sigurd highlighted the idea that the fight was a form of entertainment, a kind of 'action,' rather than a protection of self-worth or respect. The fight was not portrayed as a serious event where people could be injured, but as a way to make time pass and to experience something exciting. He also did not present fights as a regular occurrence, but as a momentary situational bid for excitement tied to a late night of partying.

Another participant, Marius, described a similar episode where he had provoked strangers on the street:

My friend and I were walking down the street and so we saw two big guys. At the time it was damn tough to talk about 'emo,' but nobody knew exactly what it was. So I like asked if he was emo, and he was just like, 'Huh, what are you talking about?!' I said, 'You like emo? Are you emo?' Then he just said, 'No!' and so I said, 'Yeah, then you are a homo?' Then he hit me.

Sigurd and Marius were not skilled or experienced fighters. Nor were they dedicated to a subculture of violence where fights were appreciated or gave them status and respect. Yet, they described episodes where they had initiated violence or provoked strangers to start a fight in the spirit of excitement. This illustrates how some young people connected their use of violence to seeking excitement when out on the town.

Kine also described an episode where her boyfriend's fighting was motivated by a search for excitement. It started out as an innocent game and friendly teasing between two friends, but escalated to a physical fight:

So, my boyfriend kind of picked a fight with his friend. He said, 'Yeah, hit me then,' jokingly. And then he did it, and he hit fucking hard. Another girl was sitting and 
watching my boyfriend. I was sitting on the armrest, so I didn't see his face, but she saw his face, and he turned totally blank. Then my boyfriend got this thing where he had to hit back. He didn't think about it before he did it, and then the other guy hit him back too. And then the fight was on.

At some point during the interaction it became about saving face and restoring self-respect, but it began as innocent provocations, just to have some fun, and to make time pass. Kine and others talked about violence as something that should be expected (and even enjoyed) when going out, but not something that should occur regularly. Hans described the same from a more general perspective: 'I think that it [fighting] is a natural consequence of going out on the town. I don't see it as a very big problem. Of course, if one is totally sober, it does not happen'. The leisure spaces these young partygoers visited typically were pubs and nightclubs in the regulated night-time economy. The temporary moral breaks of these 'play spaces' (Measham 2004), and the urge for excitement was crucial for why these fights occurred and also why they remained restrained in the severity of violence (Pedersen, Copes and Sandberg 2016).

Fights among heavy episodic drinkers were not only a response to insults and protection of self-respect, but also were an expected and integrated part of partying and nightlife. Sometimes it was even considered part of 'the fun' and one of the many exciting experiences one can have when going out. This belief that fighting can be fun is shares similarities with denying the harm of their actions (i.e., it was not serious), and more similar to what is described in studies of groups being more committed to the values of subcultures of violence (Jackson-Jacobs 2004). However, for participants in this study, fighting was not decisive for identities or roles and positions in social networks. Fights could be upsetting, but the relatively harmless nature of them led them to be seen as entertaining and exciting. 


\section{Fights from Chaos, Confusion, Drunkenness}

Not all participants were able to articulate their exact rationale for why their fights started. These episodes typically involved elements of both insults and fighting for the fun of it, but there was so much alcohol involved that drunkenness seemed to be a driving cause of the fights. At least, heavy drinking was implicated in their explanations for why the fights occurred. Kari described one incident when she ended up in a fight with one of her friends. The lead-up was that she was sad after the end of a romantic relationship. Kari thought that her friend was 'too curious' about it, and was provoked when she spoke with the former boyfriend. Kari interpreted this as a form of disrespect. However, what happened next revealed the importance of the chaos and irrationality that sometimes come with states of drunkenness:

Then I got so angry at her. I went outside. And since she's afraid of tractors, I went and stood right between two tractors so she wouldn't come after me. But then she came anyway. And I wasn't wearing any shoes, it was in the middle of the winter-I have this bad habit that if I get angry at a party, then I leave my shoes. And I was walking and trying to get away from her, and in the end, she stopped me. And then she grabbed and got a hold of my jacket, and then I got so angry. And I don't remember anything, because everything turned black. But two of my friends stood right there, and said that first I was waving my arms because I was explaining things. And then I just went at her eye.

The provocations from the friend seemed relatively mild and can hardly alone be seen as the cause of the violence. Instead, the episode was described by Kari as interwoven states of confusion and disorder caused by strong emotions and excessive drinking. Illustratively, only 
minutes after the incident she cried, apologised, and made up with her friend. In such drunken states, some participants even had a hard time recalling what the fighting had been about. Camilla described a similar fight with her sister following heavy drinking:

Camilla: And then we came home to her. And then we actually started to fight. I don't remember why, she doesn't remember why either.

Interviewer: You mean, physically?

Camilla: Yeah

Interviewer: Did you hit her?

Camilla: Yes, she sure hit me, the most. I had a black eye, I couldn't see out of that eye, and I broke a few teeth.

The interviewer continued asking, but Camilla insisted that she does not remember anything from it, adding that the entire episode was 'funny,' even though they ended up in the hospital. There were no hard feelings between the sisters afterwards.

Similarly, Gunnar described an incident where excessive intake of alcohol led to the fight:

I probably got pushed so I fell and hit my head on the concrete floor at this nightclub, and then I got this idea that someone hit me in the back of my head, so I blew up at the first one near me. It was totally the wrong person. In addition, someone I knew, to put it that way, I did a presentation with him the week before. And, so I take both of my fingers, an index fighter on both sides of the mouth and pull, so it tore up [his mouth] and everything.

Gunnar apologised the day after the event and was glad that his opponent did not go to the police. Like the aforementioned episodes, this too was connected to insults, excitement, and 
violence, but it was primarily the chaos, confusion, and misunderstandings caused by drinking that turned the relatively innocent episodes into fights.

In this first part of the analysis, we have described how relatively peaceful people describe three intertwined explanations for why they engaged in violence when drinking: They reacted to insults or looked for some kind of excitement, and mixed with a massive intake of alcohol and the party/night-life context, it eventuated into fights. The emphasis on being drunk could be seen as 'denying responsibility', a well-known neutralization technique (Sykes and Matza 1957), but we argue there is something more complex going on. As we will see more in participants' evaluations of these events later, they did not deny responsibility for what happened. Rather, they accepted responsibility and this acceptance was a major part of their story of these violent encounters.

\section{Evaluating Fights}

There are some remarkable similarities in explanations for why fights occur among persistent violent offenders, those who neutralize their violence, and heavy episodic drinkers who are otherwise not committed to violence. However, there are some important differences. It is in the evaluation of the fights that our participants most clearly differ from those who are part of violent subcultures and who boast of their violence-or those who neutralize to justify and thus continue their violence. In the second part of the analysis, we demonstrate how our participants are different from those usually studied in criminology. These differences are most clearly seen in the story evaluation where they take the blame for the violence, play down the importance of fights, and make fun of those involved - most importantly themselves. 


\section{Taking the blame}

In describing the events that led to their fights, participants were self-critical and blamed themselves for being foolish. Typically, they did this by pointing to either indiscretions of youth or to the effects of alcohol. Jon, who got into a fight about his football team, emphasised how drunk he and his friends had been: 'Of course it wouldn't have been my first reaction, but I was drunk. So there you have it.' He added that 'feelings get stronger when you're drinking'. Sigurd who was fighting at the Kebab place also highlighted that they 'were really drunk' and Eva concluded that 'it must be the booze' when trying to explain her fight. By emphasising alcohol consumption they defined the fight as being 'out of character' for them (Presser 2004), but it did not necessarily imply that they denied responsibility for what happened. Instead, they blamed themselves for having gotten that drunk in the first place or accepted the blame for what happened in other ways.

Marius who provoked strangers on the street by calling them 'emo' and 'homo,' described the episode afterwards as 'stupid'. His entire evaluation of the episode was self-critical:

It was obviously my own fault [laughter]. Super lame! I was thin as hell and small. So I got beat up, but it wasn't like this real beating, he just hit me a few times, then I fell on the ground, then he hit me in the stomach, then he just left. He was like old enough to realise that I was a little brat.

He even went as far as defending those who beat him up by saying that the violence was minor and that he deserved it. Most of the other young partygoers had similar comments that blamed themselves for the fights they had gotten involved in. Jonathan described himself as turning into a 'damn smart-ass' when he was drinking. He thought he had learned something 
from the beating he had gotten: 'I'm a little better now. ... So yeah, it's important to be put in one's place too, I think'.

This acceptance of blame was sometimes even the case when young partygoers responded to insults. Fredrik described an episode where he took a beating:

I was such a damn smartass and I actually am. I got fucking whipped. It was actually my fault. I had been at a party with some friends and then something happened. There stood some boys there, fifteen, sixteen years old, so they were fucking with a little kid, that's what he looked like to me anyway. So I was like I don't give a shit and fucked with them like, 'So cool you are' or something like that, I said to them, and so right after comes an older guy that just says, 'What did you say to my brother?' I just thought, like, fuck.

The situation ended up with both him and his friend getting beaten up. Fredrik partly blamed himself for being a coward and running off, while the friend took most of the beating, indicating some kind of commitment to the ideal of standing up for yourself. Still the evaluation of the story was that he had only himself to blame:

But it can also be that I was actually much worse than what I told you now. It might as well have been that way. And for all I know, maybe it was a good friend of theirs and stuff. It seemed like a provocation.

Even with an opportunity to turn this episode into a story about how he had defended a younger boy, Fredrik played down the moral dimension of it, instead blaming himself for the trouble he had run into and trying to defend the opponents. Similarly, Heidi who fought because of the comment about her nails made sure to communicate that she was in the wrong. When explaining what she had done, Heidi said, 'Things like that, Jesus so embarrassing, you 
know'! Later she added, 'It was just comical why I was angry'. Such self-deprecating descriptions were common, bragging about the fight or denying responsibility was not.

Participants' stories about fighting were not plotted with tales of skill at fighting or bragging about how capable they were in a fight. Instead they often went a long way to blame and distance themselves for what had happened. Their tone was apologetic, rather than boastful. They took the blame stating that they were young, drank too much alcohol, and more importantly, they had been rude and provocative. This illustrates an important difference between how violence was understood among these heavy episodic drinkers and among people who more regularly engage in violence.

\section{Talking Down the Importance of Fighting}

In violent subcultures, the amount and level of violence in fights are often exaggerated as part of creating a violent and dangerous self (see e.g. Jackson-Jacobs 2004). This was not the case for our participants. Instead, they framed their fights as being almost without violence. That is, they described fights that were short lived and involved little 'real' violence. Consequently, they emphasised that these fights had few long-lasting consequences and were not significant for life after the transgression. Indeed, friends remained friends and revenge was not sought.

Rita, who had been fighting with a classmate, told how her opponent tried to become friends again immediately after the fight they had. She accepted the offer and that was the end of their friction. Rita generalised this and described it as common in her group of friends: 'It's friends, but they just get it that something happened and then. [laughs] Then they push each other a bit, then they are best friends again. So it passes quickly'. Eva did not see her opponent until years later, but had a similar way of emphasising how the incident 
did not have any further consequences: 'Three years passed before I saw her again, and then there were no hard feelings'. Bente described an episode of fighting that ended in a meaningful talk the same night:

She was going to talk with her, but her friend got in the way and meant that she wasn't going to, there had been some arguing. But she was just like, 'But I just wanna talk,' kept going like this. So she got angry, obviously, started to hit and all that. But I actually think that they got to talk in the end. Yeah, that's how I remember it. I mean. It worked out.

Similarly, Anniken described how a group of friends of hers had a serious fight, and then became friends again: 'Now they are really good friends again, that's how it is typically. They have fought a lot, but [afterwards] they are always friends again'. In these narrative evaluations, participants downplayed the importance of the fights. While this can be seen as a 'denial of injury' (Sykes and Matza 1957), a well-known technique of neutralization, it does not seem as if this was the most important point conveyed in these stories. Instead, it can be seen as an attempt at framing them within a romantic narrative (Frye 1957), with a happy ending. Such downplaying helped to diminish the long term impact of the fight on social networks and relations. Grudges were not held and retaliation was not sought. In the end, the moral of the participants' stories was that they became friends afterwards and that the fight did not result in enduring hostility. In this way the potential consequences of the fight were minimised.

\section{Making Fun of the Fighter}

Using humour is a common way in which people fend off authority and cope with traumatic events (Tutenges and Rod 2009; Laursen 2017), including violent ones. By making jokes of 
the situation (and their role in it) people can talk about the experience, which aids in overcoming the negative emotions of it (Pogrebin and Poole 1991). Vegard for example, who was involved in a mass brawl, added in the middle of the story that 'it got to be this total laugh attack, almost like a movie scene'. In that way he not only 'talked down' the event, but he also turned it into something laughable instead of frightening.

Turning violent episodes into funny stories helped participants to establish identities as 'peaceful people'. This process can be seen in the way two of the events we have described previously became key stories for two groups of friends. Jon, who had become involved in a fight to defend a football team, explained how the incident became a humorous story that his friends enjoyed telling:

Jon: They tend to introduce it as, 'that time Jon fought for Viking' (laughter). Interviewer: You are not especially interested in football, right? Jon: No, no, no [laughter]. Interviewer: But you fight for Viking? [laughter] Okay, so then it's something that several friends of yours have in common. ... So this is something you're proud of? Jon: No, it's not something I'm proud of, but looking back at it, it is a bit funny. The fact that it was a break from what was expected from him was made this a funny event worth sharing. Jon was neither a football fan nor a fighter, and the episode was funny because he suddenly was acting out something he was not. The situation was humorous because it was absurd and out of character.

The fight Kari had with her friend-without shoes out in the winter night and being really drunk-also turned into an amusing story among her friends:

Kari: Yeah, I was called 'the Boxer' for a long time afterwards. I didn't think it was so fun to begin with, but we had our anniversary in January. We found out, this 'Boxing' 
- anniversary, so we do this countdown. She (her friend that got the punch) thinks it's so funny. I mean, she had a black eye. She said that it was quite painful, but she didn't believe that I had hit her, so I didn't understand anything. I just remember that I was angry and that my hands were sore Interviewer: But now it's been more of a funny story?

Kari: Yeah, now it's a funny story. Now it's the kind of story we tell at a party, that now it's soon 'Boxing Day' (laughs)

The clearest example of how problematic it can be to interpret these stories as neutralizations can be seen in the way many participants ridiculed those involved in fights, often in a self-deprecating manner. This is different from the hero-tales observed in subcultures of violence, where jokes are typically made at the victim's expense (Sandberg and Tutenges 2018; Dickinson and Wright 2017), or the amusing part is the brash and funny comments made by the fighter during the fight (Jackson-Jacobs 2004). It is also very different from any kind of neutralization where the point is to remove guilt by justifying what happened.

Rather than valuing their fighting exploits, participants consistently minimised their fighting. They accepted blame for the fight with shame, said it was out of character, downplayed the importance of the fight, and mocked the event and their participation in it. They did not brag about the violence or neutralize it in a way that made it natural to continue with it. As opposed to those engaged in subcultures of violence (Lauger 2014), the stories told by our participants after fights were not used in building violent identities and were not used to organise social hierarchies or social networks. Neither were they used to confirm masculinities supportive of violence (Ravn 2018). Rather they were used to distance themselves from such violent subcultures and masculinities. 


\section{Discussion}

Studies of violence often draw on gendered perceptions about the acceptability of violence, with the overwhelming majority connecting masculinity and violence (Mullins 2006, Jones 2010). These arguments are typically made from studying groups who are committed to, value or accept violence. However, the link between violence and masculinity has also been made in studies of socially integrated men. Ravn (2018: 305) suggest that being 'a proper man is not so much about either accomplishing masculinity through violence or abstaining from violence per se, but about mastering the balancing between these two opposites'. In our sample however, women and men's explanations and evaluations of fights were strikingly similar. This may reflect that the fighting was not happening within a cultural context of a masculine culture of violence or honour.

Among both male and female young Norwegians who seldom engage in violent behaviour, we still identified many of the same explanations for violence that are observed among those in marginal subcultures, for example as a restoration of respect after perceived insults or for fun and entertainment. Understanding this takes a more fluid and flexible view of subcultures than the one usually seen in subcultural studies. These typically focus on groups of people (Gelder 2005), but subcultures can also be seen as a continuum (Ilan 2015) or a collection of cultural practices that people to a greater or lesser extent can internalise, embody and exploit (Sandberg 2013). Making our analysis even more complex, we also observed that the stories of both men and women could be interpreted as neutralizations and justifications of the violence.

The main difference between our participants and those who identify with violent subcultures was in the way they evaluated their fights. Whereas those supporting violent subcultures evaluate fights positively as a means of gaining status or respect (e.g. Anderson 
1999), our participants distanced themselves from the fight and were self-critical of their actions. Most importantly, they blamed their fights on themselves-as they argued that they had behaved in stupid and provocative manners. They also minimized the violence and selfdeprecatingly distanced themselves from the violent acts they had been exposed to or had committed themselves. They did not brag about violence, portray themselves as heroic fighters, or describe stored-up aggression and the need for revenge. Instead, violence was described as temporary episodes that were 'out of character' and not reflective of their authentic or real selves. In short, they did not show adherence to subcultural values promoting violence.

In some regards, the way they spoke about the fights could be interpreted as neutralizations. Indeed, statements about how their opponents started the fight (denial of victims), protecting their honour (appeal to higher loyalties) how alcohol fuelled it (denial of responsibility), and that fights are common and not a big deal (denial of injury) are consistent with previous research on neutralizations (Maruna and Copes 2005). However, in the context of their larger stories, ones that also include evaluations of the acts, it is evident that these storylines did not do the narrative work that neutralizations usually do. One reason is that for neutralizations to be effective at removing guilt (and subsequently facilitating continuance of the behaviour) they have to be honoured by the storyteller and by the audience (Scott and Lyman 1967). What we find is that the subsequent evaluations of the fighting shows that these potential neutralizations are rejected when storytellers blame themselves. The way they make fun of themselves further illustrates this. Our study therefore shows that taking out fragments of a story and interpreting them, for example as neutralizations or as 
support for subcultural beliefs, can be problematic. Following narrative criminology (Sandberg, Tutenges and Copes 2015), it is important to analyse the complexity and ambiguity of stories and not reduce them to stringent criminological theories.

For the participants in this study violence was an exception from their ordinary life and can be understood in the context of the transgressive nightlife. Nightlife was the carnivalesque, reversed space where things out of the norm, like fighting, could happen (Haydock 2016; Tutenges 2013). Fighting in these spaces was a temporary voyage into a different sphere characterised by other cultural norms and values than they usually identified with. Arguably, the playful approach to fighting might have been made possible by participants' relatively privileged position and the absence of marginalization that otherwise often characterizes violent subcultures (e.g. Bourgois 2003). While it is clear that our participants had many opportunities for self-fulfilment and ways to get 'respect' without getting violent, we are reluctant to draw too strong conclusions about the relationship between these stories of violence and participants' socio-economic background. This is because all participants, including those from less advantaged backgrounds, shared the rejection of violence.

Our results reveal how the cultural logic of violent subcultures and honour cultures (e.g. Nisbett and Cohen 1996; Anderson 1999) stretch beyond the violence-prone populations where they are usually studied. In the moment when it happened, fighting made sense following codes inspired by cultures of violence and honour, but these cultural codes were not 'brought back' to their lives outside nightlife. Additionally, participants did not have to do neutralize their fighting, because they were not continuing their violence. Instead, it was a one-time-mistake, one that they could take the blame for, and turn into a joke. Their narrative evaluations of fighting indiscretions thus cemented and confirmed their pre-established identities as 'peaceful people'. 


\section{Conclusion}

Narrative criminology emphasises how stories instigate, sustain and effect desistance from harm (Presser and Sandberg 2015). The emphasis has been on those stories that encourage crime (but see Maruna 2001, Joosse, Bucerius and Thompson 2015). In this study however, the description of fights as out of character, the downplaying of significance of the fights and its consequences, and the way fighters made fun of themselves likely limited further violence. Our study thus reveals how stories, and in particular the narrative evaluation of critical events can have harm-reducing real-life effects. This is fundamentally different from research in subcultural and neutralization traditions that emphasize how culture and narratives makes continuous violence justifiable and thus possible. Stories of violence are critical because people 'act on the basis of stories they are caught up in' (Frank 2010: 157). If fighters interpret a fight as legitimate and important for their social identity, it can easily be assumed that it is more likely that they will engage in similar fights later. If they consider the fight resulting in them loosing face it can lead to further violence in an attempt to get their self-respect back. If people consider fights as being a mistake, accident, or of no significance for their social identity, it is more likely that they will avoid fights in the future.

Many fights take place outside of cultures approving of violence. Still, in criminology in general and qualitative criminology in particular, violence is usually studied in violenceprone populations, and the cultural codes and social identities involved are based on studies of these groups. Arguably, the consequence is a heavy bias towards descriptions of cultures of violence, or neutralizations, when describing violent behaviour. This is particularly problematic as groups continuously involved in violence are relatively small and marginal as com- 
pared to the large group of people who engage in occasional violence, for example in nightlife or as part of sessions of heavy drinking. We argue that the reasons the 'peaceful' fighters in this study give for fighting and their evaluation of fights contribute not only to understanding their violent behaviour, but also their overall desistance from it. Doing so with a narrative approach may provide theoretical insights beyond subcultural or neutralizing frameworks, especially for that large and understudied group of people that rarely engage in violence. 


\section{References}

Agnew, R. (1994), 'The techniques of neutralization and violence'. Criminology, 32(4): 555580.

Anderson, E. (1999), Code of the Street: Decency, Violence, and the Moral Life of the Inner City. New York: W.W. Norton.

Athens, L. (1997), Violent Criminal Acts and Actors Revisited. Champaign, IL: University of Illinois Press.

Bourgois, P. (2003), In Search of Respect: Selling Crack in El Barrio. Cambridge University Press.

Brookman, F., Bennett, T., Hochstetler, A., and Copes, H. (2011), 'The 'Code of the Street' and the Generation of Street Violence in the UK', European Journal of Criminology, 8(1): 17-31.

Bucerius, S. (2014), Unwanted: Muslim Immigrants, Dignity, and Drug Dealing. New York: Oxford University Press.

Collins, R. (2008), Violence: A Micro-Sociological Study. Princeton: Princeton University Press.

Copes, H., Hochstetler, A., and Forsyth, C. J. (2013), 'Peaceful Warriors: Codes for Violence Among Adult Male Bar Fighters', Criminology, 51(3): 761-94.

Dickinson, T. and Wright, R. (2017), 'The Funny Side of Drug Dealing: Risk, Humor, and Narrative Identity'. Criminology, 55: 691-720.

Ellis, A. (2016), Men, Masculinities and Violence: An Ethnographic Study. Abingdon: Routledge

Frank, A. W. (2010), Letting Stories Breathe. The University of Chicago Press.

Fraser, A. (2017), Gangs \& Crime: Critical Alternatives. London: Sage. 
Frye, N. (1957), Anatomy of Criticism: Four Essays. Princeton, NJ: Princeton University Press.

Garot, R. (2010), Who You Claim? Performing Gang Identity in School and on the Streets. New York: New York University Press.

Gelder, K. (2005), The Subcultures Reader. 2nd ed. London: Routledge.

Gong, N. (2015), 'How to Fight Without Rules: On Civilized Violence in 'De-Civilized' Spaces', Social Problems, 62: 605-20.

Harding, D. (2010), Living the Drama: Community, Conflict, and Culture among Inner-City Boys. Cambridge, MA: Harvard University Press.

Haydock, W. (2016), 'The consumption, production and regulation of alcohol in the UK: the relevance of the ambivalence of the carnivalesque', Sociology, 50: 1056-1071.

Heber, A. (2017), "You Thought You Were Superman': Violence, Victimization and Masculinities', British Journal of Criminology, 57(1): 61-78.

Hochstetler, A., Copes, H., and Forsyth, C. J. (2014), 'The Fight: Symbolic Expression and Validation of Masculinity in Working Class Tavern Culture', American Journal of Criminal Justice, 39(3): 493-510.

Ilan, J. (2015), Understanding Street Culture: Poverty, Crime, Youth and Cool. Macmillan International Higher Education.

Jackson-Jacobs, C. (2004), 'Taking a Beating: The Narrative Gratifications of Fighting as an Underdog', in J. Ferrell, K. Hayward, W. Morrison \& M. Presdee, eds., Cultural Criminology Unleashed, 231-44. Glasshouse Press.

Jacobs, B. and Copes, H. (2014), ‘Neutralization without drift: Criminal commitment among committed offenders'. British Journal of Criminology, 55(2): 286-302.

Jones, N. (2010). Between good and ghetto: African American girls and inner city violence. New Brunswick: Rutgers University Press. 
Joosse, P., Bucerius, S. M., and Thompson S. K. (2015), 'Narratives and Counternarratives: Somali-Canadians on Recruitment as Foreign Fighters to Al- Shabaab', British Journal of Criminology, 55(4): 811-32.

Katz, J. (1988), Seductions of Crime. New York: Basic Books.

Labov, W. (1972), Language in the Inner City Studies in the Black English Vernacular. University of Pennsylvania Press.

Lauger, T. R. (2014), 'Violent Stories: Personal Narratives, Street Socialization, and the Negotiation of Street Culture Among Street-Oriented Youth', Criminal Justice Review, 39: $182-200$.

Laursen, J. (2017), '(No) Laughing Allowed-Humour and the Limits of Soft Power in Prison', British Journal of Criminology, 57: 1340-58.

Lindegaard, M. R. (2018), Surviving Gangs, Violence and Racism in Cape Town: Ghetto Chameleons. London: Routledge.

MacLean, S., and Moore, D. (2014), 'Hyped Up: Assemblages of Alcohol, Excitement and Violence for Outer-Suburban Young Adults in the Inner-City at Night', International Journal of Drug Policy, 25: 378-85.

Maruna, S. (2001), Making Good. How Ex-Convicts Reform and Rebuild Their Lives. Washington, DC: American Psychological Association.

Maruna, S., and Copes, H. (2005), 'What Have We Learned From Five Decades of Neutralization Research?', Crime and Justice: A Review of Research 32: 221-320.

Matza, D., and G. M. Sykes (1961), Juvenile Delinquency and Subterranean Values. American Sociological Review, 26(5): 712-719.

Matza, D. (1964). Delinquency and drift. New York: Wiley. 
Measham, F. (2004), 'Play Space: Historical and Socio-Cultural Reflections on Drugs, Licensed Leisure Locations, Commercialization and Control', International Journal of Drug Policy, 15: 337-45.

Miller, J. M. (2011), 'Southern Culture and Crime: Considering a Theoretical Research Program for the $21^{\text {st }}$ Century', American Journal of Criminal Justice, 36: 281-92.

Morrill, C., Yalda, C., Adelman, M., Musheno, M., and Bejarano, C. (2000), 'Telling Tales in School: Youth Culture and Conflict Narratives', Law \& Society Review, 34: 521-65.

Mullins, C. W. (2006), Holding Your Square: Masculinities, streetlife and violence. Devon: Willan Publishing.

Nisbett, R.E., and Cohen, D. (1996), Culture of Honor: The Psychology of Violence in the South. Boulder, CO: Westview Press.

Pedersen, W., Copes, H., and Sandberg, S. (2016), 'Alcohol and Violence in Nightlife and Party Settings: A Qualitative Study', Drug and Alcohol Review, 35(5): 557-63.

Polletta, F., Chen, P., Gardner, B., and Motes, A. (2011), 'The Sociology of Storytelling', Annual Review of Sociology, 37(37): 109-30.

Pogrebin, M. R., and Poole, E. D. (1991), ‘Police and Tragic Events: The Management of Emotions', Journal of Criminal Justice, 19(4): 395-403.

Presser, L. (2004), 'Violent Offenders, Moral Selves: Constructing Identities and Accounts in the Research Interview', Social Problems, 51: 82-101.

Presser, L. (2012), ‘Getting On Top Through Mass Murder: Narrative, Metaphor, and Violence', Crime, Media, Culture, 8: 3-21.

Presser, L., and Sandberg, S. (2015), Narrative Criminology: Understanding Stories of Crime. New York: NYU Press. 
Ravn, S. (2018), 'I Would Never Start a Fight But: Young Masculinities, Perceptions of Violence, and Symbolic Boundary Work in Focus Groups', Men and Masculinities, 21: 291-309.

Sandberg, S, S. Tutenges and H. Copes (2015), 'Stories of Violence: A narrative criminological study of ambiguity', British Journal of Criminology, 55(6): 1168-1186.

Sandberg, S. and T. Ugelvik (2016), 'The past, present, and future of narrative criminology: An appraisal and an invitation', Crime, Media Culture, 12(2): 129-136.

Sandberg, S. and S. Tutenges (2018), 'Laughter in stories of crime and tragedy. The importance of humor for marginalized populations', Social Problems. Published online ahead of print.

Sandberg, S. (2009), 'Gangster, victim, or both? Street drug dealers' interdiscursive construction of sameness and difference in self-presentations', British Journal of Sociology, 60(3): 523-542.

Sandberg, S. (2013), 'Cannabis culture. A stable subculture in a changing world', Criminology and Criminal Justice, 13(1): 63-80.

Sykes, G. M., \& Matza, D. (1957), 'Techniques of neutralization: A theory of delinquency', American Sociological Review, 22(6): 664-670.

Tomsen, S. (1997), 'A Top Night Out. Social Protest, Masculinity and the Culture of Drinking Violence', British Journal of Criminology, 37: 90-102.

Topalli, V., Wright, R., and Fornango, R. (2002), 'Drug Dealers, Robbery and Retaliation. Vulnerability, Deterrence and the Contagion of Violence', British Journal of Criminology, 42: 337-51.

Tutenges, S. (2013), 'Stirring up effervescence: An ethnographic study of youth at a nightlife resort', Leisure Studies, 32:, 233-248. 
Tutenges, S., and Rod, M. (2009), 'We Got Incredibly Drunk ... It Was Damned Fun: Drinking Stories Among Danish Youth', Journal of Youth Studies, 12: 355-70.

Wells, S., and Graham, K. (2003), 'Aggression Involving Alcohol: Relationship to Drinking Patterns and Social Context', Addiction, 98: 33-42.

Winlow, S., and Hall, S. (2006), Violent Night: Urban Leisure and Contemporary Culture. Oxford: Berg.

Wolfgang, M., and Ferracuti, F. (1967), The Subculture of Violence. London: Tavistock. 